\title{
SURFACE VELOCITY DETERMINATION ON LARGE POLAR GLACIERS BY AERIAL PHOTOGRAMMETRY
}

\author{
by
}

\author{
H.H. Brecher
}

(Institute of Polar Studies, The Ohio State University, Columbus, Ohio 43210, U.S.A)

\begin{abstract}
Aerial photogrammetric block triangulation, a standard and well-developed technique for extending accurate control for mapping into the interior of a region from a few points of known position on its perimeter, can be readily adapted to determine surface velocities on bodies of ice which are too large, and of ten too crevassed, to be studied effectively by conventional ground surveying. Velocities are calculated from the changes in positions of the same natural surface features determined from photography of two (or more) epochs and the elapsed time. This method is capable of providing many uniformly-spaced measurements over the whole, moving, ice surface, thus allowing the production of maps of velocity and strain-rate, which are valuable in analyzing the ice-flow regime. Results from measurements completed some years ago on Byrd Glacier, one of the largest outlet glaciers from the East Antarctic plateau, are presented as an example of what the method can yield. By means of Doppler satellite surveying, relative positions of control points for each photography epoch can be determined with sub-meter accuracy, making the technique suitable also in regions where no fixed land features exist. A brief description of a project under way in such an area, on Ice Stream B in West Antarctica, is given.
\end{abstract}

\section{INTRODUCTION}

Conventional surveying to determine surface velocities is not practical on large polar valley glaciers and ice streams. The sheer size of the ice masses, which are commonly one or two hundred kilometers long and many tens of kilometers wide, usually makes it impossible to measure enough points for adequate coverage in a reasonable time. Severe crevassing of ten precludes surface travel. On ice streams, there are no vantage points for survey stations, from which to make conventional intersection surveys. Furthermore, it is usually not possible to make enough and properly distributed measurements by ground survey methods, even on smaller glaciers, to allow production of maps of velocity and strain-rate fields.

Photogrammetric aerial block triangulation is a standard, highly-developed technique for extending precise control for topographic mapping into the interior of a region from a limited number of control points of known position on the perimeter and from a few strips of points of known elevation across the region. This technique allows the determination of ice-surface velocities at essentially as many points as one wants to measure, with minimal, or, if necessary, no operation on the moving ice surface. The positions of the same natural features, such as crevasses and seracs, which are generally present in virtually unlimited numbers on rapidly moving bodies of ice, are determined at two (or more) epochs and velocities are calculated from the changes in positions and the elapsed time. The method makes it possible to provide many more measurements of surface motion and to have them spaced uniformly over the whole moving ice mass, than is usually possible with conventional field surveys. It is this capability which makes this photogrammetric technique particularly useful, because it allows the production of maps of velocity and strain-rate fields which are valuable in interpreting and analyzing the flow regime.

The accuracy of the positions of the new points determined by block aerial triangulation is essentially independent of the size of the block and depends primarily on the spacing between the perimeter control points, while the accuracy of elevations depends on the spacing of the strips of elevation control. With control-point spacing of a few air-base lengths (distances between exposures along a flight line), the positional accuracy of interior points approaches the measuring accuracy on the photographs (American Society of Photogrammetry, 1980). Measurements on the photographs accurate to a few micrometers are not uncommon; $10 \mu \mathrm{m}$ is an easily-achievable value. Resolution of mapping cameras is commonly about $15 \mu \mathrm{m}$. Generally, the smallest-scale photography which allows relevant features to be resolved, i.e. the smallest number of photographs to cover the area, will yield the highest accuracy, because accuracy improves with reduction of the number of photographs in a block. Fewer photographs also obviously minimize effort and cost. In practice, the ceiling of the photographing aircraft is of ten the limiting factor on scale. With a standard mapping camera $(15 \mathrm{~cm}$ focal length, $23 \mathrm{~cm}$ square format), it is difficult to obtain photographs at a scale smaller than 1:50000, with generally available aircraft. Both measuring accuracy and resolution at this of ten-encountered, practical limit are thus better than $1 \mathrm{~m}$ in the terrain, i.e. $0.5 \mathrm{~m}$ and $0.8 \mathrm{~m}$ respectively. Because it is often impractical to emplace strips of control points across the moving ice, poor elevation control and its effect on positional accuracy may have to be accepted. If control points can be established on fixed terrain, their positions need to be determined only once. To avoid uncertainty in identifying these on the photographs, they should be targeted with suitable markers. The technique can also be applied in "featureless" terrain, with no fixed points. In this case, positions of control points must be determined for each photography epoch and targets to mark the points are essential. Only relative positions of control points need to be known. Doppler satellite surveying allows determination of relative positions of points up to hundreds of kilometers apart and at different times, to sub-meter accuracy (Mueller, 1982) and has been applied successfully in polar conditions (e.g., Drew and Whillans, 1984).

\section{Results from Byrd Glacier, Antarctica}

Results from work on the Byrd Glacier, undertaken in 1978-79 as part of a study by Terence Hughes, of the University of Maine, and completed some time ago (Brecher, 1982), are presented as an example of what the method can be expected to yield. Similar results should be obtainable on ice stream B or elsewhere, under similar conditions.

Byrd is one of the largest and most active outlet glaciers from the East Antarctic plateau. The main ice stream is about $25 \mathrm{~km}$ wide. An area more than $100 \mathrm{~km}$ long and about $40 \mathrm{~km}$ wide was measured. Thirteen perimeter position and elevation control points, eleven on the glacier fjord walls and two on the glacier, and twelve additional elevation control points, more or less down the glacier's center line, were established (Fig.1). Surface 


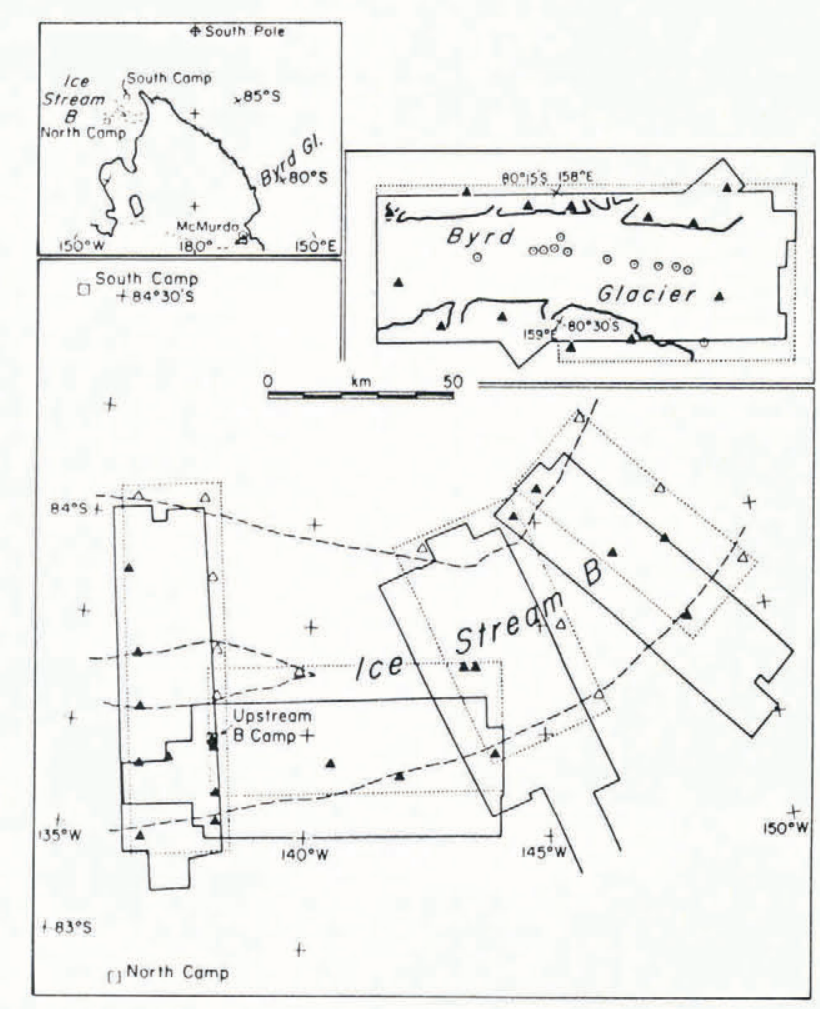

Fig.1. Overviews of photo blocks and control layout for Byrd Glacier and Ice Stream B. Triangles are position and elevation control points, circles elevation control only. Open triangles on ice stream B are control points not imaged on the photographs due to displacement of the flight lines from their desired positions. Control point positions on Ice Stream B were determined by Doppler satellite surveying relative to nearby points on stagnant ice (North and South camps) and to McMurdo and South Pole stations.

velocities were measured from two sets of aerial photographs, of 152 and 170 exposures, respectively, taken 56 days apart in the 1978-79 antarctic summer. Only the minimum number of points to form the two blocks properly were measured. Average spacing between points on the glacier was about $2.5 \mathrm{~km}$. Points were selected separately in each block for optimum location in the photogrammetric sense and then identified and marked in the other block as well. Incidentally, it is surprisingly easy to find and identify the same glacier-surface features in photographs taken at different times. Coordinates of 1467 terrain points were determined from 6738 image point measurements. Surface velocities for 601 common moving points, 472 of them on the main ice stream, were determined. The standard deviation of the photograph tie-point measurements is $16.3 \mu \mathrm{m}$, which is equivalent to $0.8 \mathrm{~m}$ in position and $1.8 \mathrm{~m}$ in elevation, at the average scale of the photographs. This appears to be a reasonable indication of the precision of the photogrammetric work. Redundancy of measurements is more than twice as large as in usual practice; the residuals approximate a normal distribution very well and only $154(1.1 \%)$ are larger than three standard deviations.

It is difficult to give a satisfactory estimate of accuracy, however, as no unambiguous checks are available. From various indirect approaches, it appears that both positions and elevations are accurate to a few meters. Taking $5 \mathrm{~m}$ as a reasonable, and perhaps too conservative, value yields errors of about $5 \%$ to $15 \%$ for all velocities except for the very lowest, near the glacier edge, where it yields about $40 \%$. Velocities agree within 2 to $4 \%$ with values reported by Swithinbank (1963) and with values from ground surveys in 1978-79 (Hughes and Fastook, 1981). Velocities determined independently by ground and photogrammetric methods at 13 common points agree within 0 to $4 \%$ and the RMS of the differences is $2 \%$. This good agreement and the "reasonableness" of the results suggest that the $5 \mathrm{~m}$ accuracy estimate, above, may be too pessimistic. A value of $3 \mathrm{~m}$ may be more realistic.

The results are presented as velocity vectors and as contours of constant total velocity and its $x$ and $y$ components. The coordinate system was chosen to make the $x$ direction parallel to the general flow direction, as judged by the vector plot (Fig.2a). The total velocity contour plot (Fig.2b) clearly shows that the dynamic center line of the glacier is displaced appreciably from the geometric center line over about two-thirds of the glacier's length and that the maximum velocity of $875 \mathrm{~m} \mathrm{a}^{-1}$ occurs well upstream on the glacier, presumably due to the buttressing effect of the Ross Ice Shelf. Not surprisingly, the $\mathrm{x}$ velocity (Fig.2c) is very similar to the total velocity and the $y$ velocity plot (Fig.2d) clearly shows the appreciable right turn, beginning about half-way down the glacier.

Figure 3 presents these results as contours of partial derivatives of the velocity components in the two orthogonal directions (strain rates). These plots were produced at the suggestion of Ian Whillans and are interpreted with his assistance, as in Whillans and others (1984). The accuracy of these velocity gradients can be estimated from the positional errors. Because positional errors are highly correlated, displacements, and thus velocities, of points close together have much smaller errors than points farther apart. Conversely, errors of velocity gradients decrease with greater spacing. Taking reasonable values of position error and spacing, one arrives at errors in velocity gradients of about $1 \times 10^{-3} \mathrm{a}^{-1}$ (or one-fifth contour interval on the plots) over distances of $8 \mathrm{~km}$ or more. Errors increase linearly to about $5 \times 10^{-3} \mathrm{a}^{-1}$ (one contour interval) for points about $1.5 \mathrm{~km}$ apart.

In the plot of $\partial v_{x} / \partial x$ (Fig.3a), extending flow at the upstream end of the glacier, a marked transition to no extension or compression in the region of maximum velocity and a hint of compression at the ice-shelf end can be seen. The plot of $\partial \mathrm{v}_{\mathrm{x}} / \partial \mathrm{y}$ (Fig.3b) shows the progressive development of a narrow shear zone against the fjord walls, particularly as the ice shelf is approached. More variation in flowline turning than is readily apparent in the vector plot is indicated in the $\partial \mathrm{v}_{\mathrm{y}} / \partial \mathrm{x}$ plot (Fig.3c). A "snaking" motion appears to be taking place at the upstream end and most of the turning to the north, farther downstream, takes place over a short distance. Lateral compression at the upstream end and spreading at the downstream end are shown by the $\partial v_{y} / \partial y$ plot (Fig.3d), but the pattern over the glacier is complex.

\section{Application to Ice Stream B. Antarctica}

The approach outlined above for regions where no fixed control points can be established, is being applied to work begun in the 1984-85 field season on Ice Stream B in West Antarctica. This ice stream is about $250 \mathrm{~km}$ long and between 40 and $90 \mathrm{~km}$ wide. To keep the field effort required to set out the necessary control points within manageable limits, four separate blocks of photographs, covering limited areas of greatest interest, were laid out. The blocks are all about $30 \mathrm{~km}$ wide and between 60 and $100 \mathrm{~km}$ long. The total area covered, about $9100 \mathrm{~km}^{2}$, is nevertheless equal to about one-third of the area of the state of Maryland, or of Belgium. About 260 photographs, at a scale of 1:52000, are involved. Figure 1 gives an overview of this project and a comparison with the size and layout of the Byrd Glacier work described above. The ice stream B project covers roughly twice the area of the Byrd Glacier work and each of the four photo blocks is about half as big as the Byrd Glacier block.

Targets of black, plastic sheeting, $3 \mathrm{~m}$ square, suspended about $0.5 \mathrm{~m}$ above the surface on an array of bamboo stakes, were used to mark ground control points. Their positions were determined relative to nearby points on stagnant ice and to McMurdo and South Pole stations by Doppler satellite surveying. They defied burial by drifting snow and destruction by wind and their images proved reasonably easy to find, even though they were, in several cases, very far from their intended positions on the photographs. Due to too great reliance by the flight crew on positioning flight lines with an insufficiently-accurate, inertial navigation system (INS), the photo blocks are displaced some 8 to $12 \mathrm{~km}$ to the north-east of their 

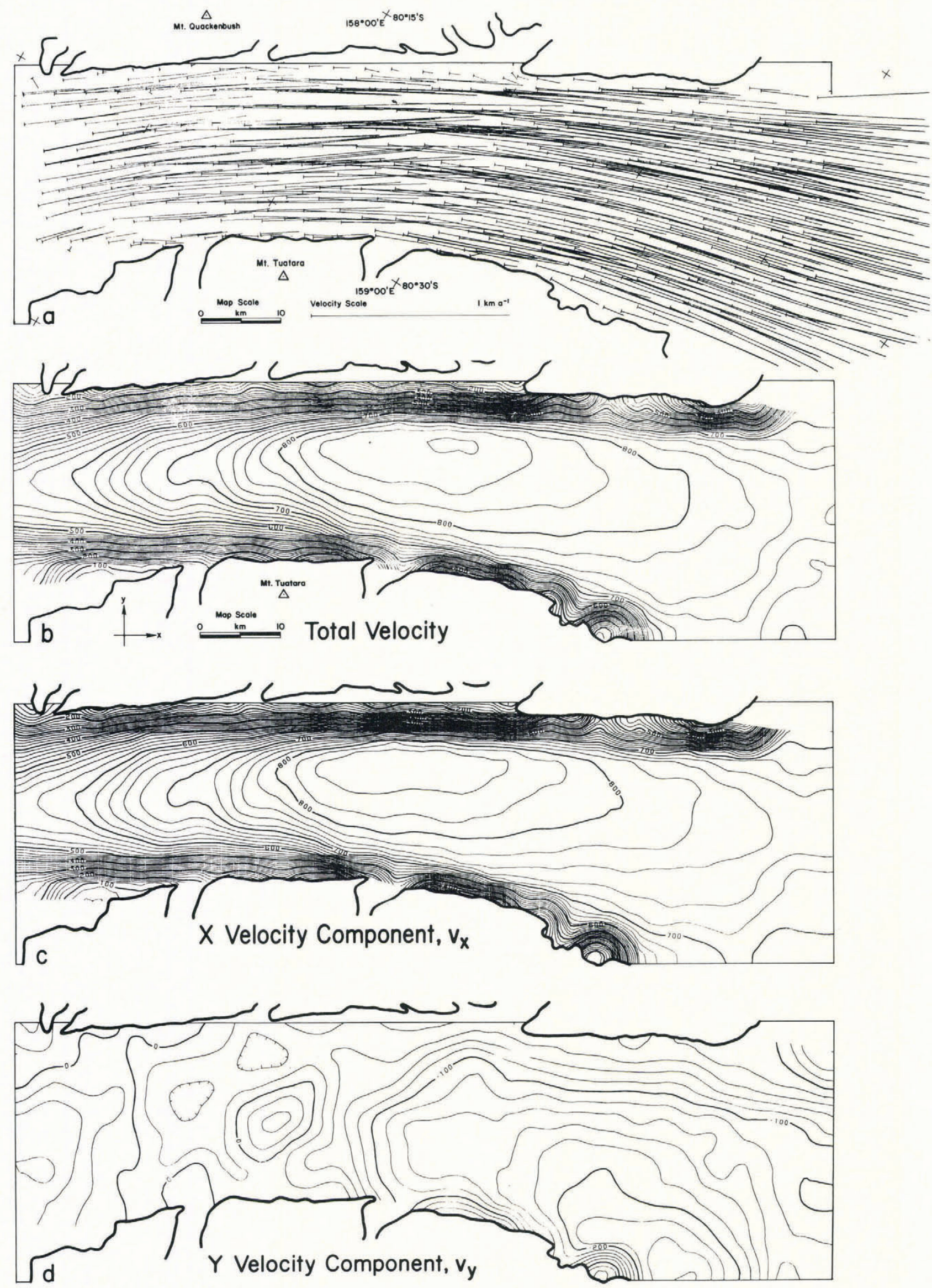

Fig.2. Surface velocity on Byrd Glacier. a) Velocity vectors, b) total velocity, c) $x$ velocity and d) y velocity contours. Contour interval is $20 \mathrm{~m} \mathrm{a}^{-1}$. Coordinate system chosen to make $\mathrm{x}$ direction parallel to general direction of ice flow. Vectors on extreme downstream end have been truncated to allow figure to fit on page. 

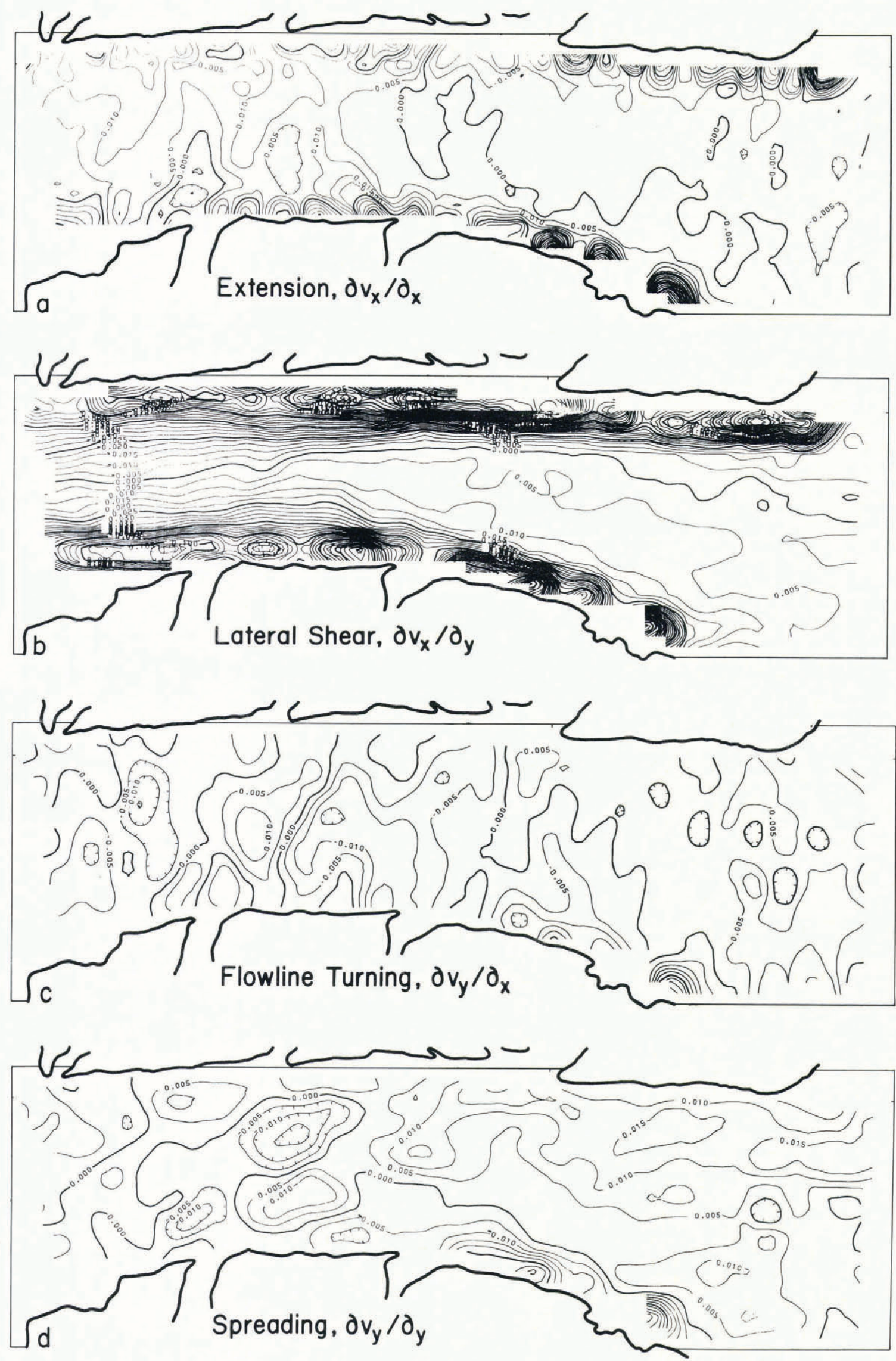

Fig.3. Contours of partial derivatives of surface velocity (strain rates) on Byrd Glacier. a) $\partial v_{x} / \partial x$, extension, b) $\partial \mathrm{v}_{\mathrm{x}} / \partial \mathrm{x}$, lateral shear, c) $\partial \mathrm{v}_{\mathrm{y}} / \partial \mathrm{x}$, flowline turning, d) $\partial \mathrm{v}_{\mathrm{y}} / \partial \mathrm{y}$, spreading. Contour interval is $5 \times 10^{-3} \mathrm{a}^{-1}$. indicates minimum distance $(8 \mathrm{~km})$ over which error is estimated to be one-fifth contour interval $\left(1 \times 10^{-3} \mathrm{a}^{-1}\right)$ or less 
intended positions and, as a result, about one third of the control points, usually along one edge of each block, were not photographed (Fig.1). Thus, only a limited part of this photography can be used for measurements. It is possible to overcome the navigation problem in relatively featureless terrain by using just one clearly-recognizable feature of known position, such as the field camp in this instance, to correct for INS drift with time and there is every reason to expect that satisfactory aerial photography will be obtained for this project.

\section{SUMMARY}

Photogrammetric aerial block triangulation is readily adaptable for measuring surface velocities on bodies of ice which are too large to study effectively by conventional ground surveys. Natural surface features are used as motion markers. Due to its capability of providing many uniformly-spaced measurements, the method allows production of maps of velocity and strain-rate fields which are valuable in analyzing and interpreting the ice-flow regime. Application of the method on Byrd Glacier indicates that results accurate to a few per cent can be obtained.

\section{ACKNOWLEDGEMENTS}

I thank Terence Hughes and Ian Whillans for the opportunities to work on Byrd Glacier and Ice Stream B, respectively. Ian Whillans prompted me to produce the partial derivative plots and guided $m e$ in attempts to interpret them. An anonymous reviewer made valuable comments and suggestions which I have attempted to incorporate. Equipment loans and other assistance for the Byrd Glacier work were provided by Lloyd Herd and Niel O'Brien of the Ohio Department of Transportation, Norman Henderson of Henderson Aerial Surveys, Steven Johnson of Virginia Polytechnic Institute and State University, the Department of Geodetic Science and the Instruction and Research Computer Center of the Ohio State University. Robert Tope drafted the figures. The work was supported by National Science Foundation grants DPP 77-22204 and 80-19962, for Byrd Glacier and 81-17235A01, for Ice Stream B.

\section{REFERENCES}

American Society of Photogrammetry 1980 Manual of photogrammetry. Fourth edition. Falls Church, VA, American Society of Photogrammetry: 397, 502-505

Brecher H H 1982 Photogrammetric determination of surface velocities and elevations on Byrd Glacier. Antarctic Journal of the United States 17(5): 79-81

Drew A R, Whillans I M 1984 Measurement of surface deformation of the Greenland ice sheet by satellite tracking. Annals of Glaciology 5: 51-55

Hughes T J, Fastook J L 1981 Byrd Glacier: 1978-1979 field results. Antarctic Journal of the United States 16(5): 86-89

Mueller I I 1982 African Doppler Survey - ADOS. In Proceedings of the Third International Geodetic Symposium on Satellite Doppler Positioning. Vol 1. Las Cruces, NM, New Mexico State University. Physical Sciences Laboratory: 645

Swithinbank C W M 1963 Ice movement of valley glaciers flowing into the Ross Ice Shelf, Antarctica. Science 141(3580): $523-524$

Whillans I M, Jezek K C, Drew A R, Gundestrup N 1984 Ice flow leading to the deep core hole at Dye 3 , Greenland. Annals of Glaciology 5: 185-190 